\title{
A fluência e sua importância para a compreensão da leitura
}

\author{
Sandra Puliez̧ - Pontifícia Universidade Católica de São Paulo, Brasil \\ Maria Regina Maluf - Pontifícia Universidade Católica de São Paulo, Brasil
}

\begin{abstract}
Resumo
A fluência na leitura vem recebendo considerável atenção nas pesquisas estrangeiras, mas ainda é pouco estudada no Brasil. O presente estudo teve como objetivo analisar a literatura recente sobre a fluência, discutindo seus componentes, desenvolvimento e relações com a compreensão da leitura. As pesquisas analisadas deixam evidente que a fluência é uma habilidade essencial, presente em todos os bons leitores, e merece a atenção dos pesquisadores pelas relações que estão sendo estabelecidas entre ela e a compreensão de texto. São feitas algumas considerações sobre as implicações do modelo teórico para a prática em sala de aula. Palavras-chave: Leitura; Fluência; Compreensão; Precisão; Prosódia.
\end{abstract}

Fluency and its importance to reading comprehension

\begin{abstract}
Reading fluency has received considerable attention in foreign studies but is still little studied in Brazil. The present study aimed to analyze the recent literature on fluency, discussing its components, development and relationships with reading comprehension. Studies analyzed shows clearly that fluency is an essential skill, present in all good readers and deserves the attention of researchers due to the relations being established between it and the text comprehension. Some thoughts on the implications of the theoretical model for classroom practice were made.

Keywords: Reading; Fluency; Comprehension; Accuracy; Prosody.
\end{abstract}

\section{Fluidez y su importancia para la comprensión de la lectura}

\section{Resumen}

La fluidez en la lectura ha recibido considerable atención en los estudios extranjeros, pero aún está poco estudiada en Brasil. El presente estudio tuvo como objetivo analizar la literatura reciente sobre la fluidez, la discusión de sus componentes, y el desarrollo delas relaciones con la comprensión de lectura. Todos los estudios analizados muestran claramente que la fluidez es una habilidad esencial, presente en todos los buenos lectores y merece la atención de los investigadores debido a las relaciones que se establecen entre éste y la comprensión de textos. Hacemos algunas reflexiones sobre las implicaciones del modelo teórico para la práctica en el aula.

Palabras clave: Lectura; Fluidez; Comprensión; Exactitud; Prosodia.

\section{Introdução}

A fluência na leitura tem recebido considerável atenção nas pesquisas estrangeiras (Coelho, 2010; Kuhn, Schwanenflugem \& Meisinger, 2010; Pikulski \& Chard, 2005), embora seja ainda pouco estudada no Brasil. Desde a publicação do National Reading Panel $[\mathrm{NRP}]^{1}$ no ano 2000 , a atenção de muitos pesquisadores voltou-se para a fluência na leitura (Hudson, Pullen, Lane \& Torgesen, 2009). Segundo esse documento, por muito tempo, durante o século $\mathrm{XX}$, os pesquisadores assumiram que a fluência era o resultado imediato da

\footnotetext{
${ }^{1}$ O National Reading Panel (NRP) é um documento produzido pela Secretaria de Educação norte-americana e o National Institute of Child Health and Human Development (NICHD), que teve como finalidade organizar as evidências de pesquisas produzidas sobre a aprendizagem e ensino de leitura sob vários aspectos. $\mathrm{O}$ documento concluiu que existem cinco competências básicas na leitura: consciência fonêmica, fônica, vocabulário, fluência e compreensão de texto.
}

proficiência no reconhecimento de palavras e por isso ela foi ignorada. Mas nas últimas três décadas, esse aspecto do desempenho em leitura foi reconceitualizado e agora procura-se entender como a instrução e a experiência em leitura contribuem para o desenvolvimento da fluência.

Um dos marcos mais importantes na concepção contemporânea de fluência na leitura veio com a publicação de LaBerge e Samuels (1974) sobre a teoria do processamento automático, da informação na leitura. Este trabalho talvez tenha sido a primeira concepção teórica moderna sobre fluência na leitura (Rasinski, 2006a). La Berge e Samuels argumentaram que o processamento das palavras na leitura (percepção visual, percepção sonora, agrupamento de palavras, etc.) deveria idealmente ser realizado em algum nível automático requerendo um mínimo de atenção ou capacidade cognitiva. Dessa maneira, os leitores poderiam reservar seus recursos cognitivos para a mais importante tarefa em leitura - a compreensão (Rasinski, 2006a).

http:/ / dx.doi.org/10.1590/1413-82712014019003009 
LaBerge e Samuels (1974) levantaram a hipótese de que, para muitos leitores, uma baixa compreensão poderia ser explicada pelo investimento alto de seus recursos cognitivos em aspectos de superfície da leitura, como, por exemplo, a decodificação de palavras lenta, trabalhosa e consciente. Esse alto investimento na decodificação esgotaria os recursos cognitivos que poderiam ser investidos na compreensão.

Após 40 anos da publicação do trabalho de LaBerge e Samuels (1974), ainda não se dispõe de uma definição clara e consensual sobre o que é a fluência na leitura. Recentemente ela foi definida por alguns teóricos como sendo a leitura precisa, rápida (com a mesma taxa da fluência oral) e com prosódia apropriada (Hudson, Lane \& Pullen, 2005; NRP, 2000).

Outros autores explicam que a fluência é expressa pela decodificação e compreensão ao mesmo tempo, tendo como indicadores de que isso está acontecendo a precisão, a automaticidade e a prosódia (Samuels, 2006). Daane, Campbell, Grigg, Goodman e Oranje (2005) afirmam que a compreensão é a parte mais importante da definição da fluência na leitura e enfatizam que a prosódia da leitura oral reflete a compreensão.

Essa variabilidade nas definições ocorre porque ler é uma tarefa complexa que requer a coordenação de múltiplas competências (Fuchs, Fuchs, Hosp \& Jenkins, 2001), mas Hudson e cols. (2009) afirmam que uma boa definição pode envolver tudo o que é importante: "a fluência na leitura é precisa, eficiente e ocorre com razoável velocidade que varia com o tipo de texto, e envolve boa compreensão do significado do texto” (p. 5).

Apesar das divergências na definição, os pesquisadores parecem concordar que existem três componentes-chave da fluência: precisão na decodificação da palavra, automaticidade no reconhecimento das palavras e uso apropriado da prosódia (Rasinski, 2006b). Vamos nos aprofundar nas características de cada um.

\section{Os três componentes da fluência na leitura}

\section{Precisão}

A precisão na leitura refere-se à habilidade de reconhecer ou decodificar as palavras corretamente. Um forte entendimento do princípio alfabético, a destreza para combinar diferentes sons e o conhecimento de um grande número de palavras são importantes na precisão de leitura de palavras (Hudson e cols., 2005).
Esse reconhecimento rápido de palavras pelo leitor é explicado por muitos pesquisadores através da teoria da leitura de palavras por reconhecimento automatizado (sight word reading) de Ehri $(2002,2005)$. Ehri (2005) argumenta que quando os olhos dos leitores acessam uma palavra muito conhecida, a identidade dessa palavra é acionada na memória e os leitores podem reconhecer sua pronúncia e significado rapidamente, sem necessidade de atenção ou de esforço para o reconhecimento das letras. Uma importante propriedade da leitura por reconhecimento automatizado é que as palavras podem ser lidas como unidades individuais, sem pausas entre suas partes, processo esse que é conhecido como unitização.

Ehri (2005) entende que algumas pessoas limitam o termo sight word, utilizando-o apenas para se referir a palavras de alta frequência vistas pelo leitor. No entanto, segundo ela, qualquer palavra que for lida um número suficiente de vezes torna-se uma palavra automatizada, que pode ser lida através da memória. Outro equívoco é considerar o reconhecimento automatizado de palavras como uma estratégia para a leitura, pois uma estratégia envolveria uma escolha de procedimentos para otimizar os resultados, e o reconhecimento de palavras acontece automaticamente, não é uma questão de escolha. Quando os indivíduos reconhecem as palavras automaticamente ao ler um texto, sabemos que essa leitura está operando inconscientemente no cérebro desses leitores.

O núcleo da aprendizagem da leitura de palavras por reconhecimento automatizado é o processo de formação das conexões. Conexões são formadas por meio das ligações que ocorrem a partir da soletração das palavras escritas com a sua pronúncia e seu significado na memória (Ehri, 1992, 2002; Perfetti, 1992). Ler uma palavra algumas vezes assegura essas conexões. E esse é o evento crítico para a aprendizagem da leitura automatizada de palavras. As conexões grafema-fonema suportam um poderoso sistema mnemônico, atuando como uma cola que une as letras de palavras escritas à sua pronúncia, na memória, juntamente com seu significado. Uma vez que o sistema de mapeamento alfabético seja conhecido, leitores podem construir um banco de palavras que serão reconhecidas automaticamente (Ehri, 2005).

Hudson e cols., (2005) explicam que a baixa precisão no reconhecimento de palavras tem uma influência negativa na compreensão e fluência de leitura. Para esses autores, a leitura imprecisa pode levar a interpretações equivocadas de um texto. 


\section{Automaticidade}

Automaticidade é um conceito comum em nossa vida cotidiana. Algumas atividades estão tão integradas em nossos hábitos diários que podemos fazê-las facilmente, com pouco esforço e com pouca atenção consciente. Dirigir é um exemplo. Quando pegamos um carro e começamos a conduzi-lo, logo estamos pensando em outras coisas que precisamos fazer. Não nos preocupamos em pisar no freio, dar seta ou trocar a marcha, simplesmente realizamos essas ações automaticamente, sem pensar. E isso é um exemplo de processamento automático.

Logan (1997) explica que no último século, especialmente a partir de meados da década de 70 , a automaticidade tornou-se um conceito familiar na psicologia experimental, tendo um papel importante na caracterização da aquisição de algumas habilidades. Quando o foco das pesquisas centrou-se nas habilidades cognitivas, a leitura passou a ser o tema central. Foi nessa época que LaBerge e Samuels (1974), conforme citado anteriormente, apresentaram sua teoria do processamento automático da informação em leitura.

Os primeiros dez anos de pesquisa sobre a automaticidade foram dedicados a distinguir as habilidades cognitivas automatizadas das não automatizadas. Os dez anos que se seguiram foram destinados a entender os mecanismos da automaticidade e relacioná-los com a memória e atenção (Logan, 1997). Com base nesses estudos, muitos pesquisadores fizeram listas com propriedades que poderiam caracterizar a automaticidade. Logan (1997) avaliou muitas dessas listas, desde a mais curta que continha três propriedades até a mais longa, com doze, e elaborou uma nova lista com quatro propriedades que considera essenciais para definir um processamento automático: velocidade, ausência de esforço, autonomia e ausência de atenção consciente.

A velocidade é considerada um critério importante, pois uma melhora na velocidade é característica do desenvolvimento da automaticidade. A performance em uma tarefa melhora com a prática. No entanto, Logan (1997) explica que esse aumento de velocidade não é ilimitado. Há uma curva de aprendizado, que é conhecida como lei de potência que indica quando um limite é atingido. Assim "a velocidade aumenta com a prática, mas os ganhos são maiores no início e diminuem com a prática contínua" (p. 125). A linha de potência claramente se aplica na automatização da leitura. Por exemplo, palavras de alta frequência que são mais praticadas pelos leitores são lidas mais rapidamente que palavras de baixa frequência (Seidenberg \& McClelland, 1989).

A ausência de esforço é a segunda propriedade da automaticidade e refere-se à facilidade com que uma tarefa é realizada. Logan (1997) diz que quando conseguimos realizar duas tarefas ao mesmo tempo, por exemplo, conversar e dirigir, sem uma interferir no desempenho da outra, então pelo menos uma delas é automatizada. Kuhn e cols. (2010) entendem que, em termos de fluência na leitura, a ausência de esforço no reconhecimento de palavras faz com que os leitores dirijam sua atenção para níveis cognitivos superiores, como ler fluentemente com compreensão. Leitores disfluentes se esforçam demais para decodificar as palavras e não conseguem integrar esse nível mais básico da leitura com níveis superiores, como a compreensão.

Além de implicar velocidade e ausência de esforço, o processamento automático é também autônomo, isto é, ele começa e continua a funcionar sem a intenção da pessoa que está realizando o ato (Logan, 1997). Por exemplo, leitores fluentes não conseguem não ler as palavras que encontram à sua frente. Quando um programa de TV apresenta legendas, mesmo que no mesmo idioma do áudio, sempre nos surpreendemos lendo-as, o que não ocorre com leitores iniciantes (Kuhn e cols., 2010).

Por fim, a última propriedade da automaticidade é a falta de atenção consciente. Uma vez que os níveis básicos na habilidade de reconhecimento de palavras se tornem automáticos, a atenção consciente a essa habilidade desaparece. Essa falta de consciência no reconhecimento de palavras faz a diferença entre leitores fluentes e disfluentes (Kuhn e cols., 2010). Os leitores disfluentes tendem a estar muito cientes dos passos que eles dão para reconhecer uma palavra em um texto, e isso faz com que o processo seja lento e deliberado.

Hudson e cols. (2009) dizem que, quando aplicadas à leitura, essas quatro propriedades que foram apresentadas são facilmente identificadas. A velocidade pode ser vista na leitura de palavras por reconhecimento automatizado e as palavras são lidas como um todo a partir da memória, o que é muito mais rápido (Ehri, 1998). A ausência de esforço é óbvia quando se observa um leitor fluente ler por horas sem interrupção ou fadiga. A autonomia é mais facilmente observada pela ausência de controle a ser exercido pelo leitor sobre o reconhecimento de palavras, uma vez que o processo de leitura ocorre mesmo 
que um leitor não deseje ler as palavras que lhe são apresentadas. Finalmente, os processos automáticos acontecem tão rapidamente que estão além do controle consciente ou da análise por parte do leitor. É impossível para um bom leitor explicar como ele lê as palavras automaticamente.

Cada uma destas quatro propriedades (velocidade, ausência de esforço, autonomia e ausência de atenção consciente) pode ser aplicada no reconhecimento automático de uma palavra, mas é importante lembrar que esses atributos desenvolvem-se de forma contínua e em tempos e velocidades diferentes, de modo que os leitores com uma quantidade intermediária de prática em leitura podem ter baixa velocidade, ainda apresentar algum esforço, ter pouca autonomia e ser parcialmente inconscientes dos processos envolvidos no ato de ler (Logan, 1997).

O documento produzido pelos pesquisadores do NRP (2000) cita o trabalho de Logan (1997) para descrever a automaticidade e enfatiza a importância da repetição para o desenvolvimento dos processos automáticos. Segundo o NRP, a automaticidade envolve o processamento de informações complexas que requerem um longo período de treinamento antes de um comportamento ser executado com pouco esforço ou atenção. Citando Ackerman (1987), o NRP (2000) informa que “...estes processos podem ser desenvolvidos apenas através de extensa prática em condições consistentes, que são típicas de muitas situações de aquisição de habilidades" (p. 7).

A pesquisa de Logan (1997) mostra isso. Ele explica que a produção científica sobre automaticidade traz a clara mensagem de que a prática é necessária para o desenvolvimento da habilidade de ler, sugerindo que os leitores ficam cada vez melhores quando há uma prática consistente em leitura.

\section{Prosódia}

A última dimensão da fluência na leitura é a habilidade de ler com prosódia, ou seja, de ler com expressão apropriada, ritmo e entonação, permitindo a manutenção do significado (Kuhn e cols., 2010).

Prosódia é a música da linguagem oral. Hudson e cols. (2005) argumentam que as características da prosódia na língua inglesa variam em entonação, padrões de acentuação tônica e tempo. Kuhn e cols. (2010) ainda acrescentam a essa lista as pausas.

A entonação é a frequência da fala. As sentenças que falamos são geralmente sinalizadas por uma elevação inicial e, em seguida, uma declinação da entonação (Kuhn e cols., 2010). Quando as sentenças se tornam mais longas, há um enfraquecimento geral da entonação (Ladd, 1984), então podemos esperar que as crianças mostrem declínio da entonação nos finais das frases quando leem textos complexos (Kuhn e cols., 2010). Uma frase com uma entonação crescente sugere que uma frase ou expressão continuará e uma entonação decrescente é indicativa de uma pausa ou do fim de um enunciado.

Os padrões de entonação não precisam ser ensinados. As crianças aprendem a ler com boa prosódia observando os padrões utilizados pelos adultos quando eles leem, ou seja, aprendem com um bom modelo de leitor (Kuhn e cols., 2010).

O segundo componente prosódico é o padrão de acentuação tônica (Hudson e cols., 2005). A acentuação tônica é uma parte importante da pronúncia. Alguns idiomas são marcadamente caracterizados pela acentuação tônica predominante das palavras. No português as palavras são predominantemente paroxítonas (cerca de $70 \%$ ) e muitas das que não são têm sinalização ortográfica indicativa. Já no inglês a acentuação tônica representa um sério problema, pela não ocorrência de um modelo predominante e à ausência de sinalização ortográfica (Schütz, 2011). Por essa dificuldade é complicado para os jovens leitores dominarem esses padrões. Muitas vezes os alunos só aprendem quando ouvem alguém falar determinada palavra por mais de uma vez.

A tonicidade pode ser usada para distinguir formas gramaticais. Um exemplo em português são as palavras "sede" (vontade de beber) e "sede" (residência) ou "leste" (do verbo ler) e "leste" (oriente). Em inglês temos permit (nominal) e permit (verbo). Cada língua, no entanto, segue o seu próprio padrão tônico. A sensibilidade a esses padrões está relacionada com o desenvolvimento da habilidade de leitura (Kuhn e cols., 2010).

Outra característica da prosódia é a duração, que se refere ao tempo de articulação de um som, sílaba ou enunciado e tem uma importância fundamental no ritmo de cada língua. A duração de cada unidade linguística varia conforme a velocidade de elocução, o que significa "que se a velocidade de produção for maior, a duração de cada elemento é menor" (Mateus, 2004, p. 3). Assim, leitores mais rápidos terão durações de segmentos mais curtas do que os leitores mais lentos. As crianças em processo de aprendizagem da leitura não são capazes de ler rapidamente e com prosódia adequada, então quando pedimos a elas 
que leiam algumas passagens de forma rápida e precisa, com certeza elas lerão com menos expressividade (Kuhn e cols., 2010).

Por fim temos a pausa, que é considerada por alguns autores como uma unidade de tempo onde não há fonação. Dois fatores originam as pausas. Primeiro podemos citar o fator fisiológico, que é determinado pela capacidade limitada dos pulmões e, assim, as pausas são necessárias para um novo armazenamento de ar pelo organismo. O segundo fator, mais importante para a prosódia, é o significativo. Quando aceitamos que toda oração é uma unidade de sentido, supomos que ela está constituída por unidades significativas menores, como as palavras, que se conectam pela semântica e pela sintaxe ao redor de um núcleo, de modo que durante a fala, ou a leitura, são delimitadas por pausas (Obediente, 2007).

Kuhn e cols. (2010) explicam que não podemos esperar que os leitores façam uma pausa no meio de uma sentença simplesmente porque eles completaram uma unidade de sentido complexa. Também não devemos considerar uma pausa no meio de uma unidade de significado como um erro. O trabalho sobre fluência de Miller e Schwanenflugel e cols. (2008) sugere que as pausas no meio de sentenças, verificada em leitores iniciantes, estão relacionadas às suas habilidades de decodificação.

Essas características juntas são muito importantes para o desenvolvimento da leitura expressiva de um texto (Dowhower, 1991). Maus leitores são frequentemente caracterizados como tendo a leitura em um tom monótono, sem expressão ou com fraseamento inadequado (Hudson e cols., 2005).

\section{A fluência como uma ponte para a compreensão}

A fluência foi uma habilidade negligenciada nas pesquisas sobre leitura no passado, mas depois que ela foi reconhecida como um dos cinco componentes principais da leitura, no relatório do NRP (2000), passou a ser o foco de atenção de muitos pesquisadores, e o número de pesquisas sobre esse assunto aumentou muito (Pikulski \& Chard, 2005).

A pesquisa que tem sido desenvolvida sobre esse tema indica que a fluência por si mesma, não é suficiente para assegurar níveis elevados de leitura, mas a fluência é absolutamente necessária para essa conquista, porque ela depende e reflete compreensão.

Depois de examinar várias maneiras de conceituar fluência, Kuhn e cols. (2010) propõem uma definição que sintetiza tudo o que apresentamos até agora:
Fluência combina precisão, automaticidade e prosódia na leitura oral, que, tomadas em conjunto, facilitam a construção de sentido do texto pelo leitor. Isto pode ser demonstrado durante a leitura oral através da facilidade no reconbecimento de palavras, na manutenşão de um ritmo adequado, fraseamento e entonação. Esses são fatores na leitura oral ou silenciosa que podem limitar ou favorecer a compreensão (p. 240).

Essa definição engloba as três dimensões da fluência, sem esquecer a compreensão. Muitos outros autores também incluem a compreensão em suas definições. Samuels (2006), por exemplo, define a fluência na leitura como "decodificação e compreensão ao mesmo tempo" (p. 39). Daane e cols. (2005) consideram que a compreensão é a parte mais importante da definição da fluência na leitura, justificando que a prosódia na leitura oral reflete compreensão.

O que tem levado esses autores a incluir a compreensão na definição de fluência são os resultados das pesquisas que estão sendo desenvolvidas. A correlação entre fluência e compreensão foi claramente estabelecida em uma análise em larga escala dos dados do National Assessment of Educational Progress in Reading (Avaliação Nacional do Progresso Educacional em leitura) (Pinnell, Pikulski, Wixson, Campbell, Gough, \& Beatty, 1995). O estudo mostra uma relação significativa e positiva entre a fluência na leitura oral e a compreensão. No entanto, ainda não há total entendimento da relação complexa que existe entre essas habilidades (Pikulski \& Chard, 2005).

Os resultados das pesquisas realizadas até agora não deixam claro se a fluência é uma causa ou uma consequência da compreensão ou se essa relação é recíproca (Kuhn \& Stahl, 2003). Stecker, Roser e Martinez (1998), em sua revisão de literatura sobre fluência, argumentam que há evidências empíricas que apoiam ambas as posições e concluem o documento avaliando que provavelmente há um relacionamento recíproco entre fluência e compreensão, uma contribuindo para o desenvolvimento da outra.

Pikulski e Chard (2005) explicam que há uma crescente concordância de que as dimensões da fluência devem ser avaliadas dentro do contexto de compreensão de leitura. A fluência sem o acompanhamento dos níveis de compreensão tem um valor muito limitado.

\section{Como desenvolver a fluência?}

O relatório elaborado pelo NRP (2000) mostra que nas últimas duas décadas que antecederam a 
publicação desse documento vários procedimentos para o desenvolvimento de fluência foram propostos e avaliados. Esses procedimentos enfatizam a leitura oral repetida ou a prática da leitura oral guiada. O objetivo dessas práticas é desenvolver hábitos de leitura fluente que permitam aos alunos ler textos de forma mais rápida, precisa, com expressão adequada e compreensão.

O documento ainda cita que o maior ganho desses procedimentos é no reconhecimento de palavras e nas medidas de fluência (velocidade de leitura), com menores efeitos evidentes na compreensão de leitura. Parece que a prática de leitura oral influencia mais as medidas que avaliam o reconhecimento de palavras e a velocidade de leitura, porém o ganho em compreensão é significativo e, em diversas pesquisas, houve uma correlação bastante elevada.

No entanto, o desenvolvimento da pesquisa na área nos anos que sucederam à publicação do NRP tem sugerido que a instrução em fluência deve fazer parte de um programa de leitura compreensiva, que enfatiza tanto a prática de leitura quanto ler para compreender.

Para Rasinski (2006b), a instrução em precisão, automaticidade e prosódia deve ocorrer junta, de uma forma integrada. Ele concorda com Hudson e cols. (2005) ao aceitar que a leitura repetida é a melhor forma para desenvolver a fluência, mas explica que, para que a leitura repetida seja interessante, é importante focar no desempenho dos leitores. Rasinski entende que existem alguns gêneros textuais que favorecem o desempenho em leitura oral, como ocorre com as poesias, canções, rimas, textos teatrais, letras de música, monólogos, diálogos e cartas. Todos esses gêneros favorecem a leitura oral com expressão e significado, não somente velocidade. Ele ainda ressalta que os estudantes que praticam a fluência com esses gêneros textuais ganham em precisão, automaticidade (velocidade), prosódia e compreensão.

A prosódia, para muitos autores, é a dimensão da fluência que mais evidencia se o leitor entendeu o texto, uma vez que o uso apropriado dos elementos prosódicos reflete compreensão (Kuhn e cols., 2010). Quando os professores incentivam os alunos a ler com prosódia, eles estão, na verdade, incentivando-os a prestar atenção ao que leem (Hudson e cols., 2009).

Hudson e cols. (2005) sugerem alguns métodos que foram projetados com a finalidade específica de desenvolver a prosódia. Um deles é a leitura de textos teatrais. Propõe-se que o professor selecione algumas obras na literatura que sejam ricas em diálogos. O professor começa lendo em vOz alta, mostrando como as emoções soam na leitura em diferentes pontos da história. Os alunos, em seguida, praticam a leitura de todo o roteiro antes dos papéis serem atribuídos. $\mathrm{O}$ ensaio entre pares fornece um propósito autêntico para reler o texto várias vezes. Esses autores indicam algumas recomendações gerais, baseadas nas evidências científicas que devem ser seguidas pelos professores para fornecer instrução em leitura e desenvolver a fluência:

- Promover um modelo de leitura oral fluente através de um professor que leia em voz alta e com repetidas intervenções de leitura;

- Fornecer instrução direta e devolutivas para ensinar a decodificação de palavras desconhecidas, ensinar expressões corretas e fraseamento adequado, o movimento de varredura dos olhos e outras estratégias que leitores fluentes usam;

- Fornecer apoio oral e modelos para os leitores usando leitura assistida, leitura de poemas, leitura emparelhada, fitas de áudio e programas de computador;

- Proporcionar aos alunos uma abundância de materiais apropriados ao seu nível de leitura para que eles leiam de forma independente;

- Oferecer muitas oportunidades para a prática de leituras repetidas de textos progressivamente mais difíceis;

- Estimular o desenvolvimento da prosódia através de pistas dos limites das expressões ou frases (p. 708).

Apesar de todas as recomendações indicadas para desenvolver fluência, Hudson e cols. (2009) expõem que ainda há muitas controvérsias sobre a melhor maneira de ensinar essa habilidade. Por esse motivo, sugerem que haja uma combinação de todos os métodos indicados para proporcionar um quadro preciso e válido sobre o desenvolvimento da fluência na leitura dos alunos.

\section{Considerações finais}

A presente revisão de literatura nos permitiu reunir informações importantes para compreendermos como caminham as pesquisas que investigam a fluência na leitura e os resultados que estão sendo encontrados. Ficou evidente que a fluência é uma habilidade essencial, presente em todos os bons leitores e merece a atenção dos pesquisadores em virtude 
da clara correlação que está sendo estabelecida entre ela e a compreensão de texto.

Deste estudo podemos retirar ao menos duas implicações psicopedagógicas. A primeira refere-se ao fato de que a instrução em fluência na leitura é algo que pode ser perfeitamente implementado em nossas escolas. As atividades de instrução são simples e possíveis de ser realizadas e com certeza irão maximizar as oportunidades de oferecer aos alunos das escolas brasileiras um ensino de melhor qualidade, ações que já estão sendo desenvolvidas em outros países.

Mas para que essas ações se concretizem, e essa é uma segunda implicação, é preciso fornecer uma formação adequada aos professores e outros profissionais da escola para que possam trabalhar com essa instrução sem transformar essa prática em algo mecânico e sem sentido, possibilitando o desenvolvimento de uma leitura automatizada, precisa e com prosódia adequada, propiciando, assim, uma melhor compreensão do texto.

\section{Referências}

Ackerman, P. L. (1987). Individual differences in skill reading: an integration of psychometric and information processing perspectives. Psychological Bulletin, 102, 3-27. Doi:10.1037/0033-2909.102.1.3

Coelho, J. R. Q. (2010). Estimulação da fluência oral: proposta de actividades e estudo exploratório. (Dissertação de Mestrado), Universidade de Lisboa, Lisboa, Portugal.

Daane, M. C., Campbell, J. R., Grigg, W. S., Goodman, M. J., \& Oranje, A. (2005). Fourth-grade students reading aloud: NAEP 2002 Special Study of Oral Reading. (NCES 2006-469). U.S. Department of Education. Institute of Education Sciences, National Center for Education Statistics. Washington, DC: U.S. Government Printing Office.

Dowhower, S. L. (1991). Speaking of prosody: fluency's unattended bedfellow. Theory Into Practice, 30, 165175. Doi: 10.1080/00405849109543497

Ehri, L. C. (1992). Reconceptualizing the development of sight word reading and its relationship to recoding. Em P. Gough, L. C. Ehri, \& R. Treiman (Eds.). Reading acquisition (pp. 107-143). Hillsdale, NJ: Erlbaum.
Ehri, L. C. (1998). Grapheme-phoneme knowledge is essential for learning to read words in English. Em J. L. Metsala, \& L. C. Ehri (Eds.). Word recognition in beginning literacy (pp. 3-40). Mahwah, NJ: Erlbaum.

Ehri, L. C. (2002). Phases of acquisition in learning to read words and implications for teaching. Em R. Stainthorp \& P. Tomlinson (Eds.). Learning and teaching reading (pp. 7-28). London: British Journal of Educational Psychology Monograph Series II.

Ehri, L. C. (2005). Learning to read words: theory, findings, and issues. Scientific Studies of Reading, 9(2), 167-188. Doi: 10.1207/s1532799xssr0902_4.

Fuchs, L. S., Fuchs, D. F., Hosp, M. K., \& Jenkins, J. R. (2001). Oral reading fluency as an indicator of reading competence: A theoretical, empirical, and historical analysis. Scientific Studies of Reading, 5, 239-256. Doi: 10.1207/S1532799XSSR0503_3.

Hudson, R. F., Lane, H. B., \& Pullen, P. C. (2005). Reading fluency assessment and instruction: what, why, and how. The Reading Teacher, 58 (8), 702-714. Doi: 10.1598/RT.58.8.1.

Hudson, R. F., Pullen, P. C., Lane, H. B., \& Torgesen, J. K. (2009). The complex nature of reading fluency: a multidimensional view. Reading \& Writing Quarterby, 25(1), 4-32. Doi: 10.1080/10573560802491208.

Kuhn, M. R., \& Stahl, S. A. (2003). Fluency: a review of developmental and remedial practices. Journal of Educational Psychology, 95 (1), 3-21. Doi: 10.1037/0022-0663.95.1.3.

Kuhn, M. R., Schwanenflugel, P. J., \& Meisinger, E. B. (2010). Aligning theory and: automaticity, prosody, and definitions of fluency. Reading Research Quarterly, 45(2), 230-251. Doi: 10.1598/RRQ.45.2.4.

LaBerge, D., \& Samuels, S. J. (1974). Toward a theory of automatic information processing in reading. Cognitive Psychology, 6(2), 293-323. Doi: 10.1016/0010-0285(74)90015-2.

Ladd, D. R. (1984). Declination: A review and some hypotheses. Phonology Yearbook, 1, 53-74.

Logan, G. D. (1997). Automaticity and reading: perspectives from the instance theory of automatization. Reading \& WritingQuarterly, 13(2), 123-146. Doi: 10.1080/1057356970130203.

Mateus, M. H. M. (2004, setembro). Estudando a melodia da fala: traços prosódicos e constituintes prosódicos. 
Conferência realizada no Encontro sobre O Ensino das Línguas e a Linguística, Setúbal, Portugal, Disponível em: 15/05/2013 de http://www.iltec. pt/pdf/wpapers/2004-mhmateus-prosodia.pdf. Acesso em: 15. mai. 2013.

Miller, J., \& Schwanenflugel, P. J. (2008). A longitudinal study of the development of reading prosody as a dimension of oral reading fluency in early elementary school children. Reading Research Quarterly, 43(4), 336-354. Doi:10.1598/RRQ.43.4.2

National Reading Panel (2000). Teacbing children to read: an evidence-based assessment of the scientific research literature on reading and its implications for reading instruction: Reports of the subgroups (NIH Publication No. 00-4754). Washington, DC: U.S. Government Printing Office. Disponível em: http://www.nationalreadingpanel.org/.

Obediente, E. (2007). Fonética y fonología. Mérida: Consejo de Publicaciones, Facultad de Humanidades y Educación, Universidad de Mérida.

Perfetti, C. A. (1992). The representation problem in reading acquisition. Em P. B. Gough, L. C. Ehri, \& R. Treiman (Eds.). Reading acquisition (pp. 145-174). Hillsdale, NJ: Erlbaum.

Pikulski, J. J., \& Chard, D. J. (2005). Fluency: bridge between decoding and reading comprehension. The Reading Teacher, 58(6), 510-519. Doi: 10.1598/ RT.58.6.2.

Pinnell, G. S., Pikulski, J. J., Wixson, K. K., Campbell, J. R., Gough, P. B., \& Beatty, A. S. (1995). Listening to children read aloud. Washington, DC: Office of Educational Research and Improvement, U.S. Department of Education.

Rasinski, T. (2004). Creating fluent readers. Educational Leadership, 61(6), 46-51.

Rasinski, T. V. (2006a). A brief history of reading fluency. Em S. J. Samuels \& A. E. Farstrup (Eds). What research has to say about fluency instruction. (pp. 4-23). Newark: International Reading Association.

Rasinski, T. V. (2006b). Reading fluency instruction: moving beyond accuracy, automaticity, and prosody. Issues and Trends in Literacy, 704-706.Doi: 10.1598/RT.59.7.10

Samuels, S. J. (2006). Toward a model of reading fluency. Em S. J. Samuels \& A. E. Farstrup (Eds.), What research has to say about fluency instruction (pp. 24-46). Newark: International Reading Association.

Seidenberg, M. S., \& McClelland, J. L. (1989). A distributed, developmental model of word recognition and naming. Psychological Review, 96, 523-568. Doi: 10.1037//0033-295X.96.4.523.

Schwanenflugel, P. J., Hamilton, A. M., Kuhn, M. R., Wisenbaker, J. M., \& Stahl, S.A. (2004). Becoming a fluent reader: Reading skill and prosodic features in the oral reading of young readers. Journal of Educational Psychology, 96(1), 119-129.doi: 10.1037/0022-0663.96.1.119

Schütz, R. (2011, 11/30). English and portuguese word stress - acentuaçãotônica de palavras. Disponível em: http:// www.sk.com.br/sk-stres.html. Acesso em: 25. Mai. 2013.

Stecker, S. K., Roser, N. L., \& Martinez, M. G. (1998). Understanding oral reading fluency. Em T. Shanahan \& F.V. Rodriguez-Brown (Eds.). 47th yearbook of the National Reading Conference (pp. 295-310). Chicago:National Reading Conference.

Torgesen, J. K., \& Hudson, R. (2006). Reading fluency: critical issues for struggling readers. Em S. J. Samuels and A. Farstrup (Eds.). Reading fluency: the forgotten dimension of reading success. Newark, DE: International Reading Association

Recebido em: 18/11/2013

Reformulado em: 26/04/2014

Segunda reformulação em: 08/06/2014

Aprovado em: 04/07/2014 
Sobre as autoras:

Sandra Puliezi é mestre em Psicologia Educacional e doutoranda na Pontifícia Universidade Católica de São Paulo. E-mail: spuliezi@gmail.com)

Maria Regina Maluf é docente na Pontifícia Universidade Católica de São Paulo e doutora em Psicologia pela Universidade de Louvain.

E-mail: marmaluf@gmail.com

Contato com as autoras:

Rua Segundo Sargento Fernando Fontes, 107

Jd. Santa Mena, Guarulhos, SP

CEP: 07096-050.

Psico-USF, Bragança Paulista, v. 19, n. 3, p. 467-475, set./ dez. 2014 
